\title{
Repression of PDK1- and LncRNA HOTAIR-Mediated EZH2 Gene Expression Contributes to the Enhancement of Atractylenolide 1 and Erlotinib in the Inhibition of Human Lung Cancer Cells
}

\author{
Qian Xiao $^{\mathrm{a}}$ Fang Zheng ${ }^{\mathrm{a}}$ Qing Tang ${ }^{\mathrm{a}}$ Jing-Jing $\mathrm{Wu}^{\mathrm{a}}$ Jianhui $\mathrm{Xie}^{\mathrm{c}}$ \\ Hai-Ding Huang ${ }^{b}$ Xiao-bo Yang ${ }^{c}$ Swei Sunny Hann ${ }^{a, c}$ \\ aLaboratory of Tumor Biology, Guangdong Provincial Hospital of Chinese Medicine, The Second Clinical \\ Medical College, Guangzhou University of Chinese Medicine, Guangzhou, bAnimal Experimental Center, \\ Guangdong Provincial Hospital of Chinese Medicine, The Second Clinical Medical College, Guangzhou \\ University of Chinese Medicine, Guangzhou, 'Guangdong Provincial Key Laboratory of Clinical Research \\ on Chinese Medicine Syndrome, Guangdong Provincial Hospital of Chinese Medicine, The Second \\ Clinical Medical College, Guangzhou University of Chinese Medicine, Guangzhou, China
}

\section{Key Words}

Atractylenolide $1 \cdot$ Erlotinib $•$ PDK1 • HOTAIR $・$ EZH2 $・$ Human lung cancer cells

\begin{abstract}
Background/Aims: We previously showed that the major bioactive compound of Atractylodes macrocephula Koidz atractylenolide 1 (ATL-1) inhibited human lung cancer cell growth by suppressing the gene expression of 3-Phosphoinositide dependent protein kinase-1 (PDK1 or PDPK1). However, the potentially associated molecules and downstream effectors of PDK1 underlying this inhibition, particularly the mechanism for enhancing the anti-tumor effects of epidermal growth factor receptor-tyrosine-kinase inhibitors (EGFR-TKIs), remain unknown. Methods: Cell viability and cell cycle distribution were measured using 3-(4, 5-dimethylthiazol2-yl)-2, 5-diphenyltetrazolium bromide (MTT) and flow cytometry assays, respectively. Western blot analyses were performed to examine the protein expressions of PDK1 and of zeste homolog 2 (EZH2). The levels of long non-coding RNA (IncRNA) and HOX transcript antisense RNA (HOTAIR) were examined via qRT-PCR. RNA-binding protein immunoprecipitation assays were used to analyze HOTAIR interaction with EZH2. The promoter activity of the EZH2 gene was determined using Secrete-Pair Dual Luminescence Assay Kit. Exogenous expressions of PDK1, HOTAIR, and EZH2 were conducted via transient transfection assays. A xenografted tumor model was used to further evaluate the effect of ATL-1 in the presence or absence of erlotinib in vivo. Results: We showed that the combination of ATL-1 and EGFR-TKI erlotinib
\end{abstract}

\footnotetext{
Swei Sunny Hann, MD, PhD, Lab. of Tumor Biology, Guangdong Prov. Hospital of Chinese Med., The Second Clinical Med. College, and Xiao-bo Yang, MD, PhD Guangzhou Univ. of Chinese Med., No. 111, Dade Road, Guangzhou, Guangdong Province, 510120 (China); Tel. 020-39318472, E-Mail hann2012@outlook.com; yangxiaobomd@163.com
} 
further inhibited growth and induced cell arrest of the human lung cancer cells, determined by both MTT and flow cytometry assays. ATL-1 inhibited the protein expression and the promoter activity of EZH2, which was reversed in cells with PDK1 overexpression. Interestingly, ATL-1 inhibited the expression levels of HOTAIR. While silencing HOTAIR inhibited the expressions of PDK1 and EZH2, overexpression of HOTAIR reduced the ATL-1-reduced PDK1 and EZH2 protein expressions and EZH2 promoter activity. In addition, ATL-1 reduced the HOTAIR binding to the EZH2 protein. Moreover, we found that exogenously expressed EZH2 antagonized the effect of ATL-1 on cell growth inhibition. Consistent with the in vitro results, ATL-1 inhibited tumor growth and the expression levels of HOTAIR, protein expressions of EZH2 and PDK1 in vivo. Importantly, there was synergy of the combination of ATL-1 and erlotinib in this process. Conclusion: Here, we provide the first evidence that ATL-1 inhibits lung cancer cell growth through inhibiting not only the PDK1 but also the IncRNA HOTAIR, which results in the reduction of one downstream effector EZH2 expression. The novel interplay between the HOTAIR and EZH2, as well as repressions of the PDK1 and HOTAIR coordinate the overall effects of ATL-1. Importantly, the combination of ATL-1 and EGFR-TKI erlotinib exhibits synergy. Thus, targeting the PDK1- and HOTAIR-mediated downstream molecule EZH2 by the combination of ATL-1 and erlotinib potentially facilitates the development of an additional novel strategy to combat lung cancer.

(C) 2018 The Author(s)

Published by S. Karger AG, Basel

\section{Introduction}

Lung cancer is one of the most aggressive malignancies and is a leading cause for cancer deaths worldwide with the highest incidence and mortality rate [1]. Lung carcinoma is commonly classified as small cell lung cancer (SCLC) and non-small cell lung cancer (NSCLC), and the latter accounts for approximately $80-85 \%$ of all cases. The current standard of treatment for lung cancer is the surgical resection followed by adjuvant radiation therapy and chemotherapy, as well as new targeted therapies. However, the 5-year survival rate is still low despite advances in diagnostics and therapeutics due to early detection deficiency, resulting in recurrence and metastasis [1,2]. The small-molecule inhibitors of epidermal growth factor receptor-tyrosine-kinase inhibitors (EGFR-TKIs), such as erlotinib or gefitinib, have been well established as a therapeutic option for a well-defined subset of lung cancer patients $[3,4]$. However, almost all patients eventually acquire resistance to these TKIs, which is a major obstacle of this otherwise promising therapeutic approach $[4,5]$. Thus, a detailed understanding of the mechanisms underlying this development and progression of NSCLC is essential to improving the diagnosis, prevention, and therapy. In addition, finding alternative novel therapeutic modalities, especially for enhancing the treatment efficacy of EGFR-TKIs for lung cancer patients is also greatly desirable.

Natural products have been considered as potential agents for the prevention and treatment of cancer. Atractylenolide I (ATL-I) is a natural sesquiterpene lactone and one of the main naturally occurring compounds isolated from Atractylodes macrocephala Koidz. It shows a wide spectrum of pharmacological functions such as anti-inflammatory, antioxidant, and anti-tumor effects on various cell types including cancer cells [6-10]. One study showed that AT-I potently inhibited proliferation and induced apoptosis through inactivating the notch pathway in gastric cancer cells [11]. Another report found that ATL-I significantly sensitized the response of ovarian carcinoma cells to paclitaxel by reducing the protein expression of IL-6, vascular endothelial growth factor (VEGF), and survivin, thus enhancing apoptosis and cell growth inhibition. This suggests that the combination of ATL-I and paclitaxel may be considered as a promising strategy for the treatment of ovarian carcinoma [10]. We previously demonstrated that ATL-1 inhibited the growth of lung cancer cells through the extracellular signal-regulated kinase 1/2 (ERK1/2)-mediated suppression of transcription factor signal transducer and activator of transcription 3 (Stat3) and SP1 protein, resulting in inhibition of PDK1 gene expression [12]. However, the detailed molecular mechanism underlying the anti-lung cancer effects still remains unknows. 
Long noncoding RNAs (lncRNAs) are defined as transcribed RNA molecules that are longer than 200 nucleotides and have no obvious protein coding capacity. Among these, HOX transcript antisense intergenic RNA (HOTAIR), a noncoding RNA transcribed from the HOXC locus with an approximate length of $2.2 \mathrm{~kb}$, has been reported to reprogram chromatin organization and promote tumor progression. Overexpression of HOTAIR has been shown in several types of human cancers and has been linked to metastasis, cancer progression, and epithelial-to-mesenchymal transition through multiple signaling mechanisms. Thus, the importance of HOTAIR in cancer biology has sparked interest toward using HOTAIR as a biomarker and potential therapeutic target [13-15]. Silencing of HOTAIR or inhibition of miR-125a-5p promoted cancer cell apoptosis by releasing caspase 2 in several cancer cells [16]. HOTAIR levels were highly expressed in serous ovarian cancer (SOC) tissues compared to normal controls. Furthermore, the overexpression of HOTAIR correlated with an advanced stage and a high histological grade of ovarian cancer. Thus, HOTAIR is an independent prognostic factor for predicting the overall survival of SOC patients [17]. HOTAIR can be explored as a biomarker in lung cancer because its elevated expression in lung tumor tissues is correlated with metastasis, drug resistance, and poor survival in patients with lung cancer [13]. Nevertheless, the potential link and the detailed mechanism underlying the true role of this IncRNA with regard to the occurrence, growth, and progression of lung malignancy still remains undetermined.

The enhancer of zeste homolog 2 (EZH2) is a histone methyltransferase unit of polycomb repressor complexes that has been shown to pocess oncogenic and tumor promoter effects through multiple mechanisms, resulting in stimulated growth and tumor progression in various cancer types [18-20]. Increasing evidence indicated that elevated expression of EZH2 was observed in many malignant tumors and was significantly associated with poor outcome in cancer patients [21]. Thus, pharmacological inhibition of EZH2 or agents triggering EZH2 degradation are promising therapeutic strategies for the treatment of various cancer types [22-24]. In studies that assess the relationship between EZH2 expression and the clinical outcomes in patients with colorectal cancer treated with anti-EGFR therapeutics, the authors showed that EZH2 expression was associated with the survival in patients with colorectal cancer who were treated with anti-EGFR therapeutics. This suggests that the EZH2 expression is a useful additional prognostic biomarker for anti-EGFR therapy [25]. In addition, one report found that IncRNA-ANCR could influence the invasion and migration of colorectal cancer cells by specifically binding to EZH2, thus regulating EZH2 expression [26]. Several natural herbals have been shown to serve as EZH2 modulators through the inhibition of histone trimethylation, the reduction of the matrix metalloproteinase gene, the modulation of tumor-suppressive microRNAs, the interaction with other transcription factors, and tumor promoters. In addition to others, they influence tumor growth, apoptosis, and progression in several cancer types [27]. We previously showed that polyphyllin I (PPI), a bioactive phytochemical extracted from the Rhizoma of Paris polyphylla, inhibited the growth of lung cancer cells through stress-activated protein kinase/c-Jun N-terminal kinase (SAPK/JNK)-mediated inhibition of p65; this results in the reduction of DNA methyltransferase 1 (DNMT1) and EZH2 gene expression [28]. $\beta$-elemene, a compound extracted from Curcuma wenyujin, inhibited the cell growth of nasopharyngeal carcinoma via inactivation of Stat3, and the reduction of DNMT1 and EZH2 expressions [29]. While the connections between PDK1 and HOTAIR have not been shown, the links of HOTAIR and EZH2 have been reported in several other studies. The post-transcriptional regulation of gene expression plays an important role in cellular processes; mRNA binding proteins can regulate the translation of functionally related gene products and subsequent biological cellular functions via coordinated binding to subsets of mRNAs. HOTAIR has been reported to have the ability to bind to EZH2, resulting in stimulation of tumor growth, progression, and metastasis [30-32]. However, the underlying molecular mechanism for the herbals, especially ATL-1 in combination with other agents such as EGFR-TKI in the treatment of cancer still has yet to be elucidated. 


\section{Cellular Physiology Cell Physiol Biochem 2018;49:1615-1632 \begin{tabular}{l|l|l} 
DOI: 10.1159/000493497 & (C) 2018 The Author(s). Published by S. Karger AG, Basel
\end{tabular} and BIOChemistry $\frac{\text { Published online: } 14 \text { September, } 2018 \text { www.karger.com/cpb }}{\text { Xiao et al.: Repression of EZH2 Gene Expression by the Combination of Atractylenolide }}$ 1 and Erlotinib}

Here, we extended these studies and found that ATL- 1 alone or in combination of EGFRTKI erlotinib inhibited lung cancer cell growth through the repression of the PDK1- and HOTAIR-mediated inhibition of EZH2 expression.

\section{Materials and Methods}

\section{Reagents and cell culture}

The antibody against EZH2 was purchased from Cell Signaling Technology Inc. (Beverly, MA, USA). The PDK1 antibody was obtained from Abcam (Cambridge, MA, USA). The MTT agent was purchased from Sigma Aldrich (St. Louis, MO, USA). The reagent Lipofectamine 3000 was obtained from Life Technologies (AB \& Invitrogen, Carlsbad, CA, USA). ATL-1 was purchased from Chengdu Must Bio-technology Company (Chengdu, Sichuan, China). All other chemicals were purchased from Sigma Aldrich (St. Louis, MO, USA) unless otherwise indicated. NSCLC cells (A549 and H1299) were obtained from the Chinese Academy of Sciences Cell Bank of Type Culture Collection (Shanghai, China) and were cultured at $37^{\circ} \mathrm{C}$ in a humidified atmosphere containing $5 \% \mathrm{CO}_{2}$. The culture medium consisted of RPMI 1640 medium (Life Technologies, Carlsbad, CA, USA) supplemented with $10 \%(\mathrm{v} / \mathrm{v})$ heat-inactivated fetal bovine serum (Thermo Fisher Scientific Inc, Waltham, MA, USA), $100 \mu \mathrm{g} / \mathrm{ml}$ streptomycin, and $100 \mathrm{U} / \mathrm{mL}$ penicillin. In addition, Geneticin (G-418) Sulfate (Life Technologies, Carlsbad, CA, USA) was included at a concentration of $200 \mu \mathrm{g} / \mathrm{mL}$ for culturing A549-Luc cells (obtained from the Guangzhou Land Technology Co., Guangzhou, China). Once a $60-70 \%$ confluence was reached, the cells were digested with $0.25 \%$ trypsin for all other experiments.

\section{Cell viability assay}

Cell viability was examined using the 3-(4, 5-dimethylthiazol-2-yl)-2, 5-diphenyltetrazolium bromide (MTT) assay as previously reported [33]. NSCLC cells $\left(2 \times 10^{4}\right.$ cells/well) seeded into 96-well plates were treated with indicated agents for up to $48 \mathrm{~h}$. Afterwards, MTT solution $(10 \mu \mathrm{L}, 5 \mathrm{~g} / \mathrm{L})$ was added and incubated at $37^{\circ} \mathrm{C}$ for an additional $3 \mathrm{~h}$. After removing the supernatant, the solvent dimethyl sulfoxide (DMSO, $150 \mu \mathrm{L}$ ) was added and oscillated for 5-10 min. Finally, the optimal density was recorded at 490 nm absorbance using a microplate reader (Perkin Elmer, Victor X5, Waltham, MA, USA). The percentage of viable cells for the treatment group was calculated by adjusting the untreated control group. Combinationinduced synergy was analyzed and expressed as a combination index (CI), using CompuSyn (ComboSyn, Inc., Paramus, NJ, USA), following the method developed by Chou and Talalay [34].

\section{Quantitative real-time PCR ( $q R T-P C R)$}

The mRNA expression of HOTAIR was routinely quantified via quantitative real-time-PCR (qRT-PCR). The primers used in this study were designed as follows: HOTAIR forward 5'-GGTAGAAAAAGCAACCACGAAGC-3; reverse 5'-ACATAAACCTCTGTCTGTGAGTGCC-3; GAPDH forward 5'- AAGCCTGCCGGTGACTAAC -3'; reverse 5'- GCGCCCAATACGACCAAATC -3'. QRT-PCR was performed in a $20 \mu \mathrm{L}$ mixture containing $2 \mu \mathrm{L}$ of the cDNA preparation, $10 \mu \mathrm{L} 2 \times$ SYBR Green Premix ExTaq, and $10 \mu \mathrm{M}$ primers on an ABI 7500 Real-Time PCR System (Applied Biosystems Inc, Grand Island, NY, USA). The qRT-PCR protocol included an initial step of $95^{\circ} \mathrm{C}$ for $30 \mathrm{sec}$, followed by $40 \mathrm{cycles}$ of $95^{\circ} \mathrm{C}$ for $3 \mathrm{sec}$, and annealing at $60^{\circ} \mathrm{C}$ for $30 \mathrm{sec}$. Each sample was tested in triplicate. Threshold values were determined for each sample/primer pair and the $2^{-\Delta \Delta c t}$ method was used to calculate the relative expression levels of HOTAIR.

\section{HOTAIR SIRNA transfection}

The HOTAIR small interfering RNA (HOTAIR siRNA) and scrambled control siRNA (control siRNA) were purchased from GenePharma (GenePharma, Shanghai, China). The target sequences for HOTAIR siRNAs were as follows: The sequences of siRNA were:

si-HOTAIR1, 5'-GCCUUCCUUAUAAGCUCGU-3', 5'-ACGAGCUUAUAAGGAAGGC-3';

si-HOTAIR2, 5'-CAAUAUAUCUGUUGGGCGU-3', 5'-ACGCCCAACAGAUAUAUUG-3';

si-HOTAIR3, 5'-GGAAGCUCUUGAAGGUUCA-3', 5'-UGAACCUUCAAGAGCUUCC-3'.

A549 and H1299 cells $\left(2 \times 10^{5} /\right.$ well) were transfected with a final concentration of $50 \mathrm{nM}$ siRNAs, targeting the HOTAIR and control for $24 \mathrm{~h}$ using the Lipofectamine 3000 Transfection Reagent (Invitrogen, 


\section{Cellular Physiology Cell Physiol Biochem 2018;49:1615-1632 \\ \begin{tabular}{l|l|l} 
and Biochemistry Published online: 14 September, 2018 & $\begin{array}{l}\text { (c) } 2018 \text { The Author(s). Published by S. Karger AG, Basel } \\
\text { www.karger.com/cpb }\end{array}$
\end{tabular}}

Xiao et al.: Repression of EZH2 Gene Expression by the Combination of Atractylenolide

1 and Erlotinib

CA, USA) as per the manufacturer's directions. Following the transfections, the cells were harvested for all other experiments.

\section{Western blot analysis}

The Western blot procedure was conducted as previously described [33]. In brief, equal amounts of proteins from cell lysates were applied on SDS polyacrylamide gels and transferred onto polyvinylidene difluoride (PVDF) Membranes (Millipore, Billerica, MA, USA), then incubated with antibodies, such as PDK1 and EZH2 $(1: 1000)$ at $4^{\circ} \mathrm{C}$ overnight. Subsequently, the membranes were incubated with a secondary antibody conjugated to horseradish peroxidase (1:3000, Cell Signaling, Beverly, MA, USA). Finally, the membranes were transferred to a freshly prepared ECL solution (Immobilon Western; Millipore, Billerica, MA, USA) and immunoreactive bands were visualized using chemiluminescent reagent and quantitated by Image Lab software (Bio-Rad, Hercules, CA, USA).

\section{RNA binding protein immunoprecipitation (RIP)}

The RNA binding protein immunoprecipitation assay was performed with a Magna RIP ${ }^{\mathrm{TM}}$ RNA-Binding Protein Immunoprecipitation Kit (Millipore, Temecula, CA, USA) according to the instructions provided by the manufacturer. Briefly, A549 and H1299 cells at 80-90\% confluence were lysed in RIP lysis buffer on ice after washing in PBS and were then stored at $-80^{\circ} \mathrm{C}$ until further use. Magnetic beads were prepared by initial PBS washes followed by incubation with primary antibody raised against EZH2 ( $5 \mu \mathrm{g}$ of total antibody used per immunoprecipitation) at room temperature for $30 \mathrm{~min}$. Extensive washes were performed prior to incubation of absorbed magnetic beads with previously collected cell lysates. Incubation of conjugated beads with the lysate was conducted overnight at $4^{\circ} \mathrm{C}$ with rotation. The beads were then thoroughly washed and digested with proteinase $\mathrm{K}\left(30 \mathrm{~min}\right.$ at $\left.55^{\circ} \mathrm{C}\right)$ to disengage $\mathrm{EZH} 2$ containing ribonucleoprotein (RNP) complexes. RNA from the immunopurified RNPs were harvested via canonical phenol chloroform isoamyl extraction and further precipitated via ethanol. The immunoprecipitated RNA from the EZH2-RNPs was then subjected to cDNA synthesis and qPCR analysis.

\section{Transient transfection assays}

The procedure was conducted as described in a previous study [35]. Briefly, cells were seeded at a density of $2.5 \times 10^{5}$ cells/well in 6-well dishes and grown to $60 \%$ confluence. For each well, $2 \mu \mathrm{g}$ of the control or wild type pEZX-PG04-EZH2 promoter constructs (purchased from GeneCopoeia, Inc., Rockville, MD, USA) with or without $0.2 \mu \mathrm{g}$ of internal control secreted alkaline phosphatase (SEAP) were co-transfected into cells with the Lipofectamine 3000 reagent. The preparation of cell extracts and measurement of luciferase activities were determined using the Secrete-Pair Dual Luminescence Assay Kit (GeneCopoeia, Inc., Rockville, MD, USA) and normalized with SEAP activity within each sample. In the separated experiment, $2 \mu \mathrm{g}$ of control (pCMV6) and the expression constructs containing Myc/FLAG-tagged ORFs of human PDK1 and EZH2, and control (pcDNA3.1) or pcDNA 3.1-HOTAIR obtained from OriGene Technologies, Inc. (Rockville, MD, USA) and GeneCopoeia, Inc, respectively, at a final concentration of $2 \mu \mathrm{g} / \mathrm{mL}$, were transfected into the cells with the Lipofectamine 3000 reagent. The cells were then incubated for $24 \mathrm{~h}$ at $37^{\circ} \mathrm{C}$ and treated with ATL- 1 for the indicated time for all other experiments.

\section{In vivo xenograft model of human lung tumor growth}

Animal studies were performed according to protocols approved by the Institutional Animal Care and Use Committee of Guangdong Provincial Hospital of Chinese Medicine (with Ethics Approval Number 2017036) and the National Institutes of Health Guide for the care and use of Laboratory animals (NIH Publications No. 8023, revised 1978). A total of 40 eight-week-old female nude mice obtained from Beijing Vital River Experimental Animal Co. Ltd. (Beijing, China) were maintained at the Animal Center of Guangdong Provincial Hospital of Chinese Medicine. A549 cells, carrying the luciferase reporter gene (A549-Luc, obtained from the Guangzhou SoJuBio Technology Co., Guangzhou, China) (1x107 cells), were subcutaneously injected into the mice. Xenografts were allowed to grow until initial measurement (100$150 \mathrm{~mm}^{3}$ ) was obtained using calipers. Mice were randomly divided into control and ATL-1 (75 mg/kg), erlotinib alone (50 mg/kg), and the combination of ATL-1 and erlotinib groups, which were administered daily via intraperitoneal injection for up to 20 days ( $n=10$ per group) according to previous studies [3638] Next, mice were anesthetized via inhalation of $2 \%$ isoflurane. The substrate D-luciferin (Caliper Life 


\section{Cellular Physiology Cell Physiol Biochem 2018;49:1615-1632

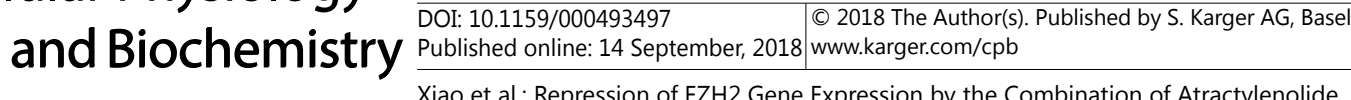 \\ 1 and Erlotinib}

Sciences, Hopkinton, MA, USA) was injected into the peritoneal cavity at a dose of $150 \mathrm{mg} / \mathrm{kg}$ in $100 \mu \mathrm{L}$. The intensity of bioluminescence imaging (BLI) signal was determined using the IVIS-200 Imaging System (Xenogen/Caliper, Alameda, CA, USA). Tumor volume measurements were calculated using the formula for an oblong sphere: volume $=\left(\right.$ width $^{2} \times$ length $) \times 2$. Quantification of bioluminescence was reported as photons/sec. The body weights of the mice were measured once a week. All mice were euthanized on day 20 in accordance with the Guide for the Care and Use of Laboratory Animals. The corresponding xenografted tumors were removed and weighed, and then processed for the detection of the PDK1 and EZH2 protein levels by Western blot, and HOTAIR levels by qRT-PCR.

\section{Statistical analysis}

Almost all data were expressed as mean \pm SD of three independent experiments. Differences between groups were assessed by one-way ANOVA and significance of difference between particular treatment groups was analyzed by Tukey's Multiple Comparison Test for multiple comparison using GraphPad Prism software version 5.0 (GraphPad Software, Inc. La Jolla, CA, USA). Asterisks in the figures indicate significant differences of experimental groups in comparison with the corresponding control condition. A $P$-value below 0.05 was deemed significant.

\section{Results}

Combination of ATL-1 and EGFR-TKI further inhibited growth and induced cell cycle arrest of lung cancer cells

We previously showed that ATL-1 inhibited lung cancer cell growth by suppressing PDK1 gene expression [12]. In the current study, we tested whether ATL-1 could enhance the anti-tumor effect of EGFR-TKI erlotinib. We observed that the combination of ATL-1 (70 $\mathrm{mg} / \mathrm{mL})$ and erlotinib $(10 \mu \mathrm{M})$ further inhibited growth in A549 and H1299 cells (Fig. 1A). The CI values were 0.42805 and 0.66521 in A549 and H1299 cells, respectively, indicating moderate synergy. Subsequently, we examined the nature of the cell cycle arrest induced by ATL- 1 . We found that A549 and H1299 cells treated with ATL-1 in either presence or absence of erlotinib for $24 \mathrm{~h}$ resulted in an increase in the proportion of cells at the G0/ G1 phase, while reducing that of cells at the S phase by ATL-1 or erlotinib alone; stronger effects were seen in the combination treatment group as detected via flow cytometry (Fig. 1B). These results suggest that the combination of ATL-1 and erlotinib exerted enhanced effects in the inhibition of lung cancer cell growth.

ATL-1 inhibited the mRNA levels of HOTAIR independent of PDK1

Although the current understanding of the transcriptional gene regulation is extensive, posttranscriptional gene regulation still remains largely unexplored. The increased expression of IncRNA has recently been shown to be involved in cancer cell growth through the regulation of PDK1 signaling [39]; to further clarify the precise functions of lncRNA signaling in this process, we first examined the effect of ATL-1 on HOTAIR, one of the lncRNA in the current study. We found that ATL-1 inhibited the mRNA levels of IncRNA HOTAIR in A549 and H1299 cells (Fig. 2A). Interestingly, we observed that the silencing of HOTAIR inhibited cell growth and also PDK1 protein expression in both A549 and H1299 cells (Fig. 2B-C). In contrast, overexpression of HOTAIR blocked the ATL-1-inhibited PDK1 protein expression (Fig. 2D), while exogenously expressed PDK1 had no effect on the ATL-1-inhibited HOTAIR mRNA levels (Fig. 2E). In summary, the results above indicate that HOTAIR acted upstream of PDK1 and that ATL-1 inhibited the expression of HOTAIR, thus reducing the PDK1 protein levels in this process. 


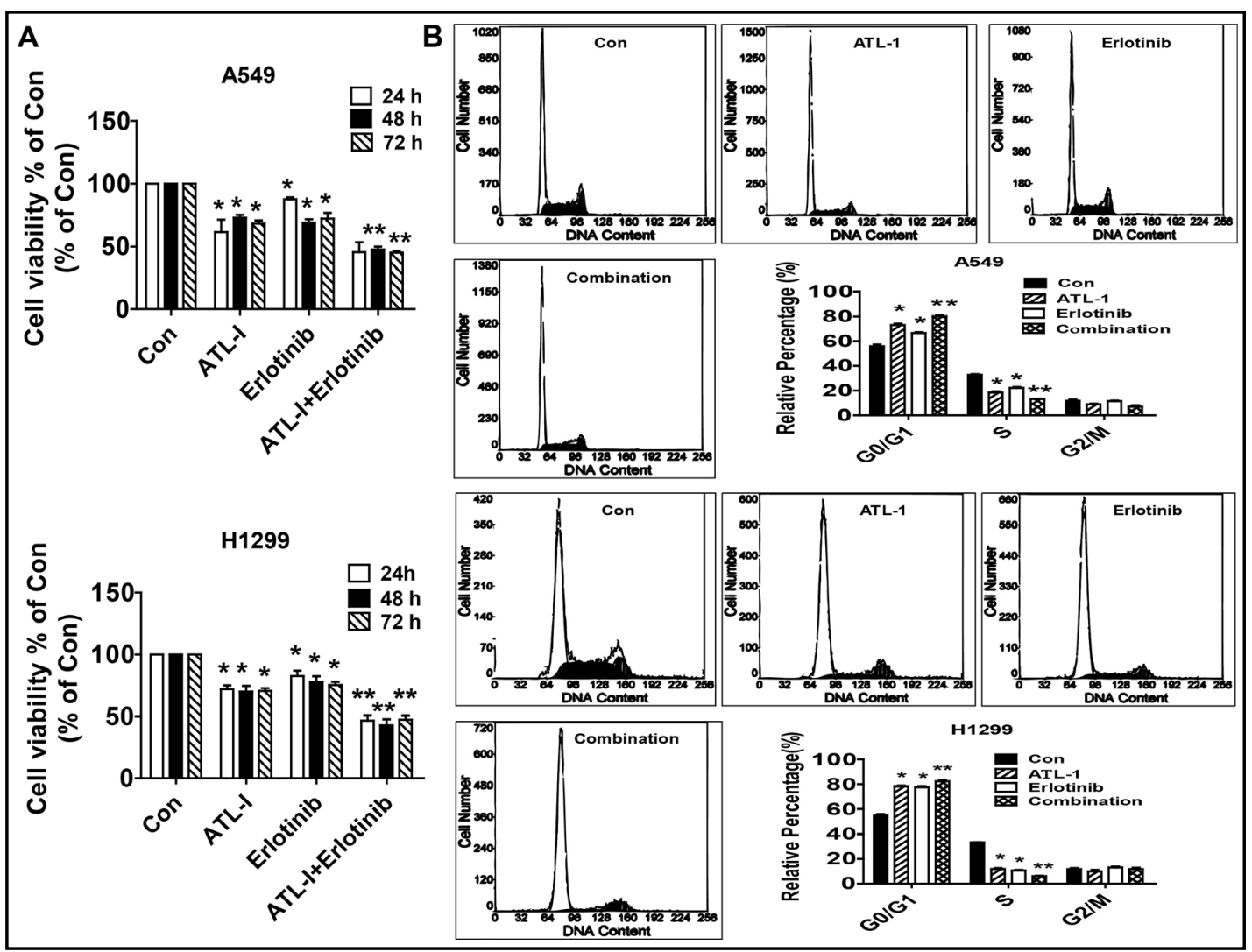

Fig. 1. Combination of ATL-1 and EGFR-TKI further inhibited growth and induced cell cycle arrest of lung cancer cells. A, A549 and H1299 cells were treated with ATL-1 (70 mg/mL) and gefitinib (10 $\mu \mathrm{M})$ for $24 \mathrm{~h}$, followed by measuring cell viability by MTT assays and the Chou-Talalay method expressed as CI values as described in the Materials and Methods section, respectively. B, A549 and H1299 cells were treated with ATL-1 $(70 \mathrm{mg} / \mathrm{mL})$ and erlotinib $(10 \mu \mathrm{M})$ for up to $24 \mathrm{~h}$. Afterwards, the cells were collected and processed for analysis of the cell cycle distribution via flow cytometry. The percentages of the cell population in each phase (G0/G1, S and G2/M) were assessed by Multicycle AV DNA Analysis Software. *indicates significant difference as compared to the untreated control group $(\mathrm{p}<0.05)$.

\section{ATL-1 reduced EZH2 expression through inhibition of PDK1 and HOTAIR}

We further assessed the potential downstream effectors of PDK1 and HOTAIR. Because the oncogenic and tumor promoter effects of EZH2 and links to HOTAIR [18-20, 40], we started to examine the EZH2 expression in this process. We showed that ATL-1 inhibited protein expression of EZH2 in A549 and H1299 cells (Fig. 3A). Interestingly, overexpressed PDK1 was found to overcome the effect of ATL-1 on the expression of EZH2 protein (Fig. 3B) and the promoter activity (Fig. 3C) in A549 and H1299 cells.

Moreover, as expected, while silencing HORAIR reduced the EZH2 protein levels (Fig. 4A), the excessive expression of HOTAIR neutralized the ATL-1-reduced EZH2 protein and the promoter activity (Fig. 4B-C); notably, HOTAIR-resisted ATL-1-reduced EZH2 protein was not observed in cells with silenced PDK1 gene (A549 and H1299; Fig. 4D). The findings indicate that the repressions of PDK1 and HOTAIR were involved in the ATL-reduced EZH2 expression at both translational and transcriptional levels. The latter was required in the presence of PDK1 in this process. Several studies have shown HOTAIR to be physically associated with EZH2, leading to regulation of EZH2 and other gene expressions in various cancer cells [32, $41,42]$. Thus, in the current study, to further test whether HOTAIR is associated with EZH2 protein, RIP experiments were performed on cell extracts using antibodies against EZH2. We observed that ATL-1 reduced HOTAIR RNA binding to EZH2 protein (Fig. 4E), suggesting that 


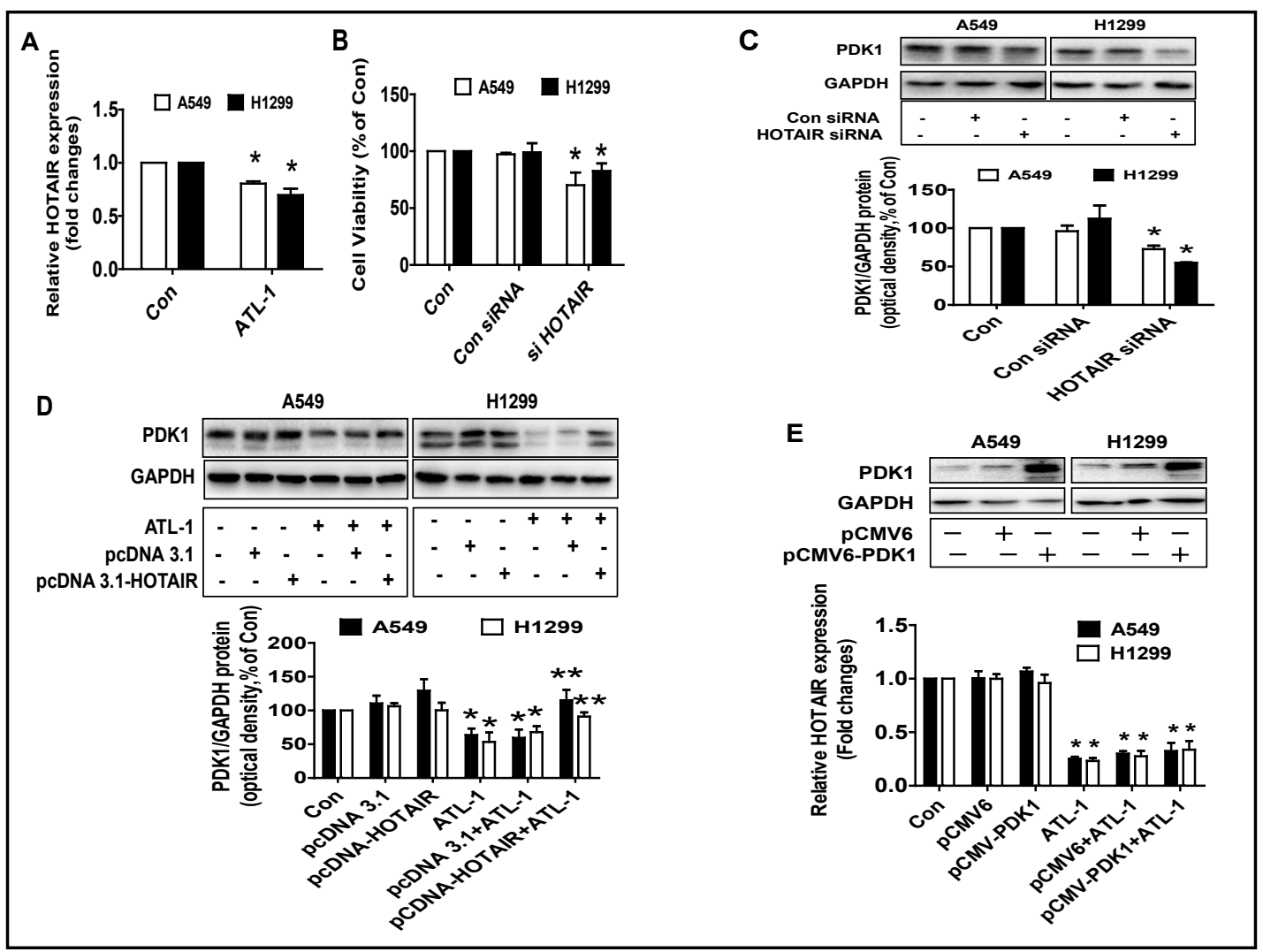

Fig. 2. ATL-1 inhibited the levels of HOTAIR independent of PDK1. A, A549 and H1299 cells were exposed to ATL-1 for $24 \mathrm{~h}$, followed by measuring the levels of HOTAIR by qRT-PCR. B-C, A549 and H1299 cells were transfected with the control or HOTAIR siRNAs for $24 \mathrm{~h}$ before exposing to ATL- 1 for an additional $24 \mathrm{~h}$, followed by measuring the cell growth and the PDK1 protein expression by MTT and Western Blot, respectively. D, A549 and H1299 cells were transfected with the control and the HOTAIR overexpression vector for $24 \mathrm{~h}$ before exposing the cells to ATL-1 for an additional $24 \mathrm{~h}$. Afterwards, the PDK1 protein was determined by Western Blot. E, A549 and H1299 cells were transfected with the control and PDK1 overexpression vector for $24 \mathrm{~h}$ before exposing the cells to ATL-1 for an additional $24 \mathrm{~h}$. Afterwards, the HOTAIR levels were determined by qRT-PCR. Insert on the upper panel represented the protein levels of PDK1 as determined by Western blot. GAPDH was used as an internal control. The figures are representative cropped gels/blots that have been run under the same experimental conditions. Values in bar graphs were given as the mean \pm SD from three independent experiments. *indicates significant difference as compared to the untreated control group $(\mathrm{P}<0.05)$. ${ }^{* * i n d i c a t e s ~ s i g n i f i c a n t ~ d i f f e r e n c e ~ f r o m ~ t h e ~ A T L-1 ~ a l o n e ~}(\mathrm{P}<0.05)$.

the physical association between EZH2 protein and HOTAIR mRNA may also be involved in the anti-lung cancer effect of ATL-1 in this process.

\section{Effects of the combination of ATL-1 and erlotinib on the expressions of PDK1, HOTAIR, and EZH2}

We further investigated whether there was an additive potential or synergy of the combination of ATL-1and EGFR-TKI erlotinib in this process. Other studies demonstrated the more beneficial responses of the combining of either ATL-1 [10] or erlotinib with other agents in the inhibiting tumor growth [43]. As expected, we found that the combination of ATL-1 and erlotinib further inhibited the expressions of PDK1, EZH2 proteins, and HOTAIR levels in A549 and H1299 cells (Fig. 5A-C). The aforementioned results indicated additive or synergistic effects. 


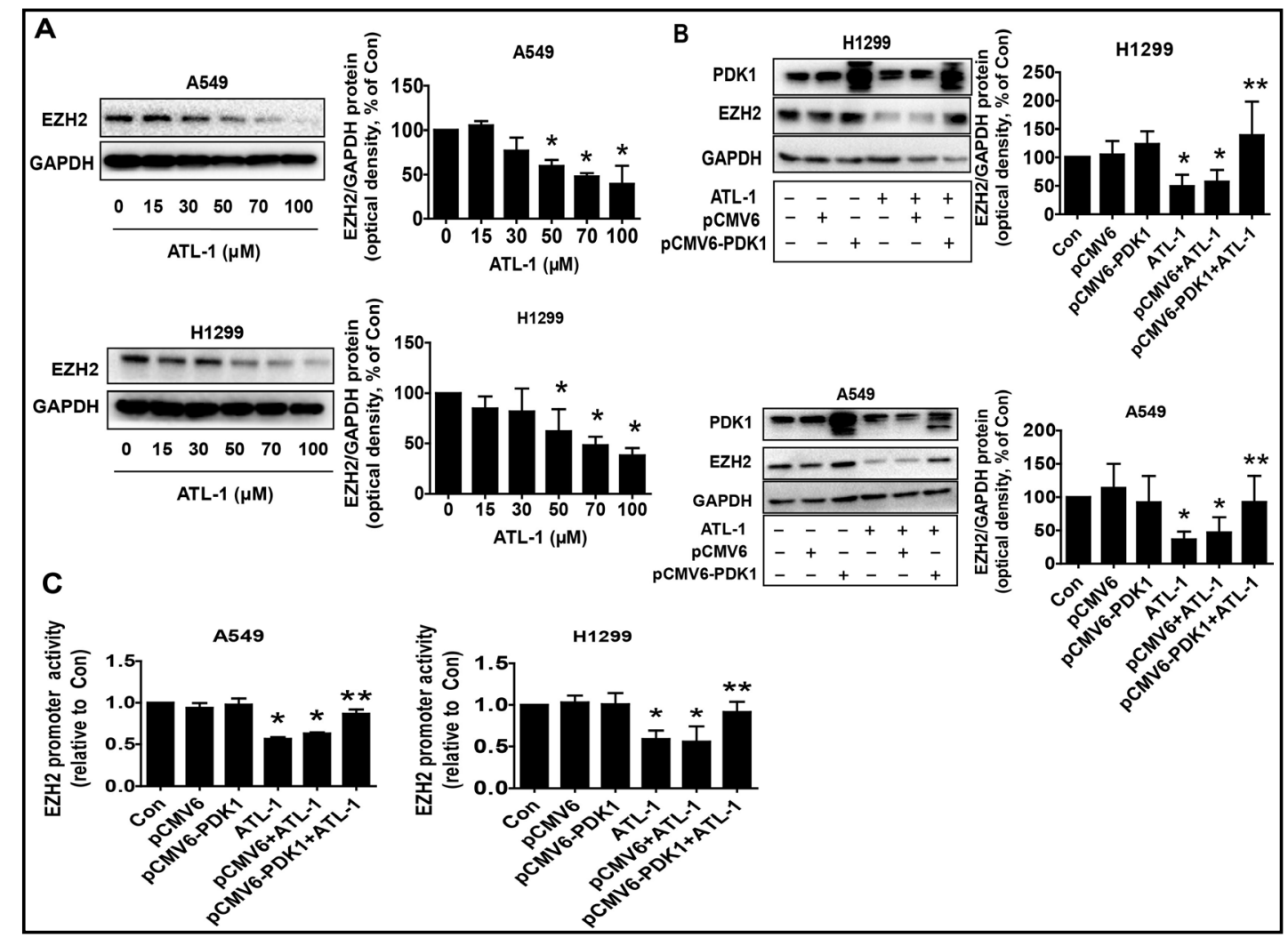

Fig. 3. ATL-1 reduced EZH2 expressions through inhibition of PDK1. A, A549 and H1299 cells were treated with indicated doses of ATL-1 for $24 \mathrm{~h}$. Afterwards, the cell lysate was harvested and the protein expression of EZH2 was measured by Western blot. GAPDH was used as loading control. B, A549 and H1299 cells were transfected with the control and the PDK1 overexpression vectors for $24 \mathrm{~h}$ before exposing the cells to ATL-1 for an additional $24 \mathrm{~h}$. Afterwards, the cell lysate was harvested and the protein expression of EZH2 was measured by Western blot. C, A549 and H1299 cells were transfected with the control and the PDK1 overexpression vectors, and with a wild type human EZH2 promoter reporter construct ligated to luciferase reporter gene and an internal control secreted alkaline phosphatase for $24 \mathrm{~h}$, followed by treating with ATL1 for an additional $24 \mathrm{~h}$. Afterwards, the promoter activities were determined using the Secrete-Pair Dual Luminescence Assay Kit as described in the Materials and Methods section. Values in bar graphs were given as the mean \pm SD from three independent experiments. *indicates significant difference as compared to the untreated control group $(\mathrm{P}<0.05)$. ${ }^{* *}$ indicates significant difference from the ATL-1 alone $(\mathrm{P}<0.05)$.

\section{Overexpressed EZH2 had no effect on PDK1 and HOTAIR}

Given the observations of the potential links of PDK1, HOTAIR, and EZH2 in this process, we examined the potential regulatory loops among these next. We showed that either excessive expressed EZH2 had no effect on the ATL-1-redcued PDK1 protein or HOTAIR mRNA levels in A549 and H1299 cells (Fig. 6A-B). However, exogenously expressed EZH2 overcame ATL-1-inhibited cell growth (Fig. 6C). These findings indicated that inhibition of EZH2, which is one of the downstream effectors of PDK1 and HOTAIR, was required to mediate the inhibitory effect of ATL-1 on lung cancer cell growth.

\section{ATL-1 inhibited tumor growth, HOTAIR expression levels, and protein expressions of PDK1} and EZH2 in vivo

To further investigate the antitumor effects of ATL-1 in combination of EGFR-TKI in vivo, we labeled A549 cells with a luciferase reporter system. The activity of ATL-1 against the growth of lung cancer cells in vivo was examined in A549-Luc cancer xenografts in nude mice. The tumor progression rate was assessed via in vivo luciferase bioluminescent imaging. We showed that in the treatment group, the signals in the tumor are significantly lower than that 


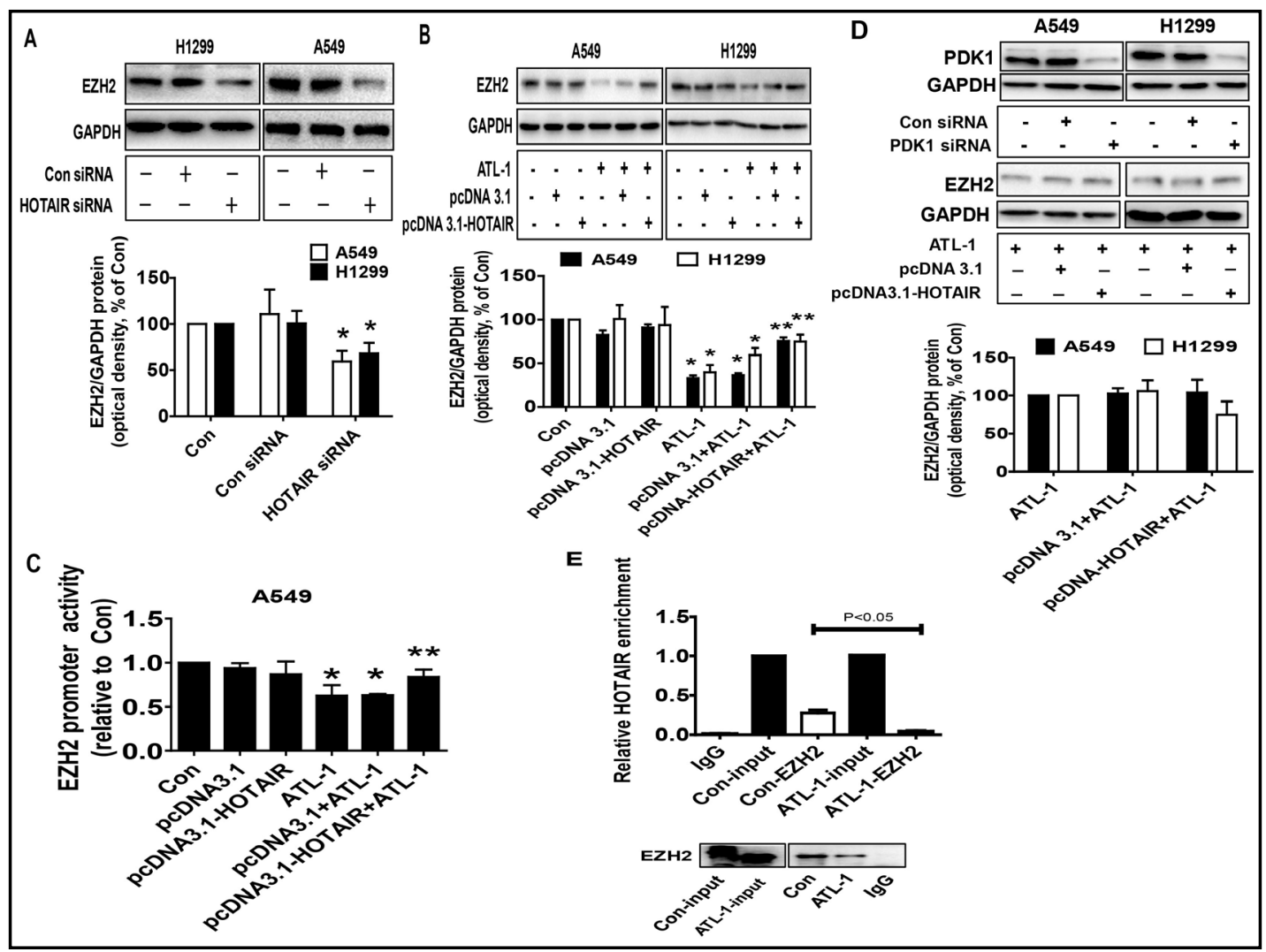

Fig. 4. ATL-1 reduced EZH2 expressions through inhibition of HOTAIR. A, A549 and H1299 cells were transfected with the control or HOTAIR siRNAs for $24 \mathrm{~h}$ before exposing to ATL-1 for an additional 24 $\mathrm{h}$, followed by measuring the EZH2 protein expression by Western Blot. B, A549 and H1299 cells were transfected with the control and the HOTAIR overexpression vectors for $24 \mathrm{~h}$ before exposing the cells to ATL-1 for an additional $24 \mathrm{~h}$. Afterwards, the EZH2 protein expression was determined by Western blot. C, A549 cells were transfected with the control and the HOTAIR overexpression vectors, and a wild type human EZH2 promoter reporter construct ligated to luciferase reporter gene and an internal control secreted alkaline phosphatase for $24 \mathrm{~h}$, followed by treating with ATL-1 for an additional $24 \mathrm{~h}$. Afterwards, the promoter activities of EZH2 were determined using the Secrete-Pair Dual Luminescence Assay Kit as described in the Materials and Methods section. The figures are representative cropped gels/blots that have been run under the same experimental conditions. D, A549 and H1299 cells were transfected with the control or the PDK1 siRNAs, followed by exposing the cells to the control and the HOTAIR overexpression vectors for $24 \mathrm{~h}$ before exposing the cells to ATL-1 for an additional $24 \mathrm{~h}$. afterwards, the PDK1 and EZH2 protein levels were measured by Western Blot. E, Cells lysates from A549 cells treated with ATL-1 for 24 $\mathrm{h}$, Afterwards, Immunoprecipitations were performed using the anti-EZH2 monoclonal antibody and the IgG1 isotype control. The levels of HOTAIR in immunoprecipitates were examined by qRT-PCR. The relative enrichment of the HOTAIR was determined after normalized to the input. Values in bar graphs were given as the mean \pm SD from three independent experiments. *indicates significant difference as compared to the untreated control group $(\mathrm{P}<0.05)$. ${ }^{* *}$ indicates significant difference from the ATL-1 alone $(\mathrm{P}<0.05)$.

in the vehicle-treated control one (Fig. 7A). Administration of ATL-1, erlotinib alone, and a combination of both with a dosage of $75 \mathrm{mg} / \mathrm{kg} /$ day (ATL-I) and erlotinib (50 mg/kg) caused a significant suppression of growth of the established A549 xenografted tumors compared to that of the vehicle-treated control animals as shown via tumor weight and sizes (Fig. 7BD). Moreover, consistent with the results of the in vitro data, the reduced expressions of PDK1, EZH2, and HOTAIR from fresh tumors that were harvested from the afore-mentioned experiment were observed in the ATL-1, or erlotinib-treated groups compared to that in the control group (Fig. 7E-F). It is worth noting that the combination treatment showed even greater inhibitory effects (Fig. 7E-F). 


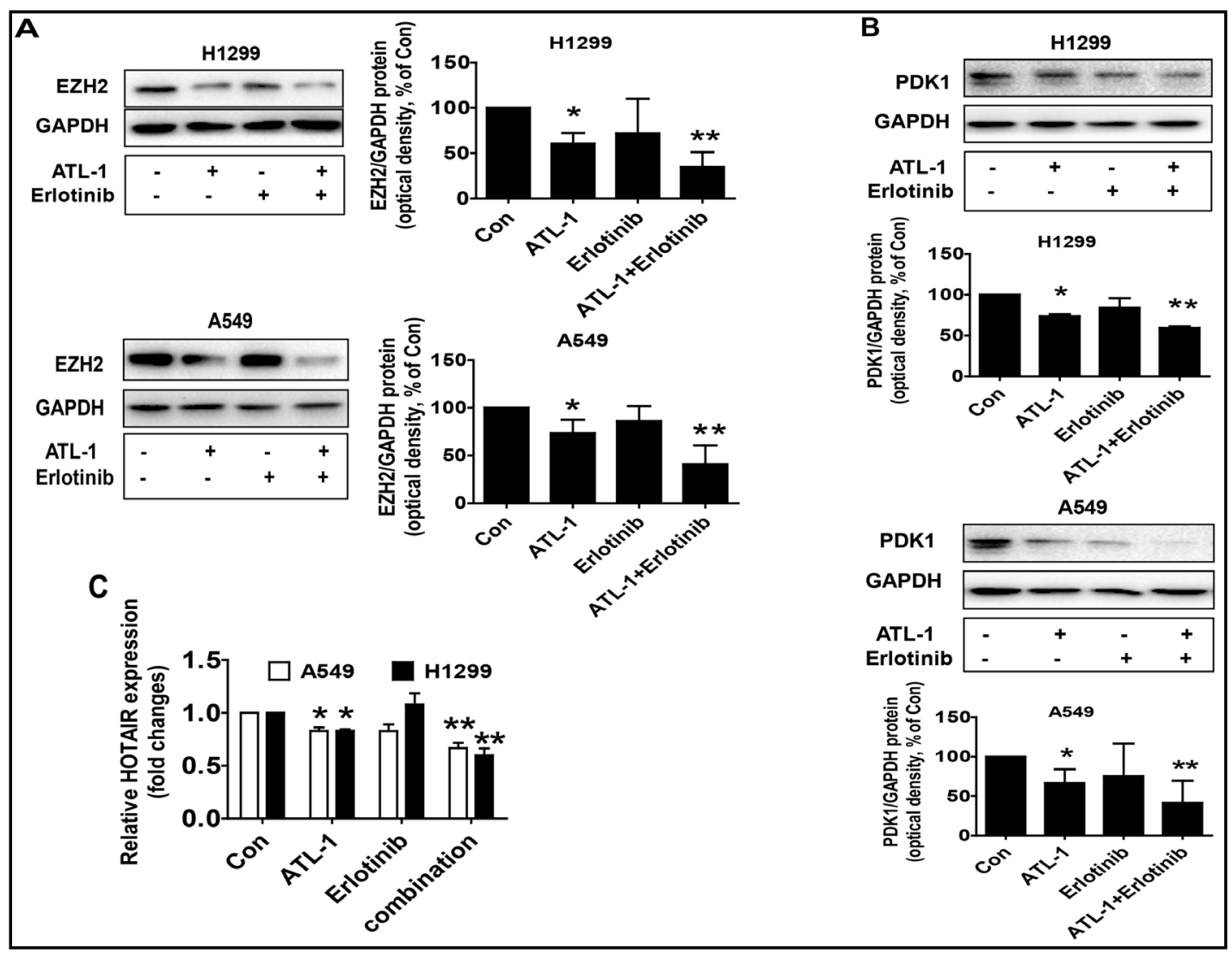

Fig. 5. The effects of the combination of ATL-1 and erlotinib on the expressions of PDK1, HOTAIR and EZH2. A-C, A549 and H1299 cells were treated with ATL-1 (70 mg/mL) and erlotinib (10 $\mu$ M) for $24 \mathrm{~h}$, followed by measuring the PDK1, EZH2 protein expressions, and HOTAIR mRNA levels by Western blot and qRT-PCR, respectively. The figures are representative cropped gels/blots that have been run under the same experimental conditions. Values in bar graphs were given as the mean \pm SD from three independent experiments. *indicates significant difference as compared to the untreated control group $(\mathrm{P}<0.05)$. $* *$ indicates significant difference from the ATL-1 alone $(\mathrm{P}<0.05)$.

\section{Discussion}

ATL-1 has been shown to have anti-tumor effects in various cell types including lung cells [6-10]. We recently demonstrated that ATL-1 inhibited the growth of lung cancer cells through ERK1/2-mediated suppression of transcription factors Stat3 and SP1 protein levels, resulting in inhibition of PDK1 gene expression [12]. In the current study, we demonstrated the potential synergy of the combination of ATL-1 and one EGFR-TKI erlotinib on lung cancer cell growth. We observed that the inhibition of the tumor drivers PDK1 and IncRNA HOTAIR, resulting in the reduction of EZH2 gene expression, contributed to the overall synergistic effects of the combination of ATL-1 and erlotinib.

Previously, we reported the role of PDK1 in mediating the anti-lung cancer effect of ATL-1. In the current study, we further explored the potential targets associated with the regulation of PDK1 that may also be involved in the effect of ATL-1 in the presence or absence of EGFR-TKI erlotinib. Our results indicate the role of IncRNA HOTAIR expression in mediating the anti-tumor effect of ATL-1, suggesting that the interaction and repression of the PDK1 and HOTAIR were involved in the effect of ATL-1 in this process. HOTAIR plays a critical role in the gene regulation and chromatin dynamics and appears to be disregulated in a variety of cancers. The expression of HOTAIR is elevated in lung cancer and correlates 
Xiao et al.: Repression of EZH2 Gene Expression by the Combination of Atractylenolide

1 and Erlotinib

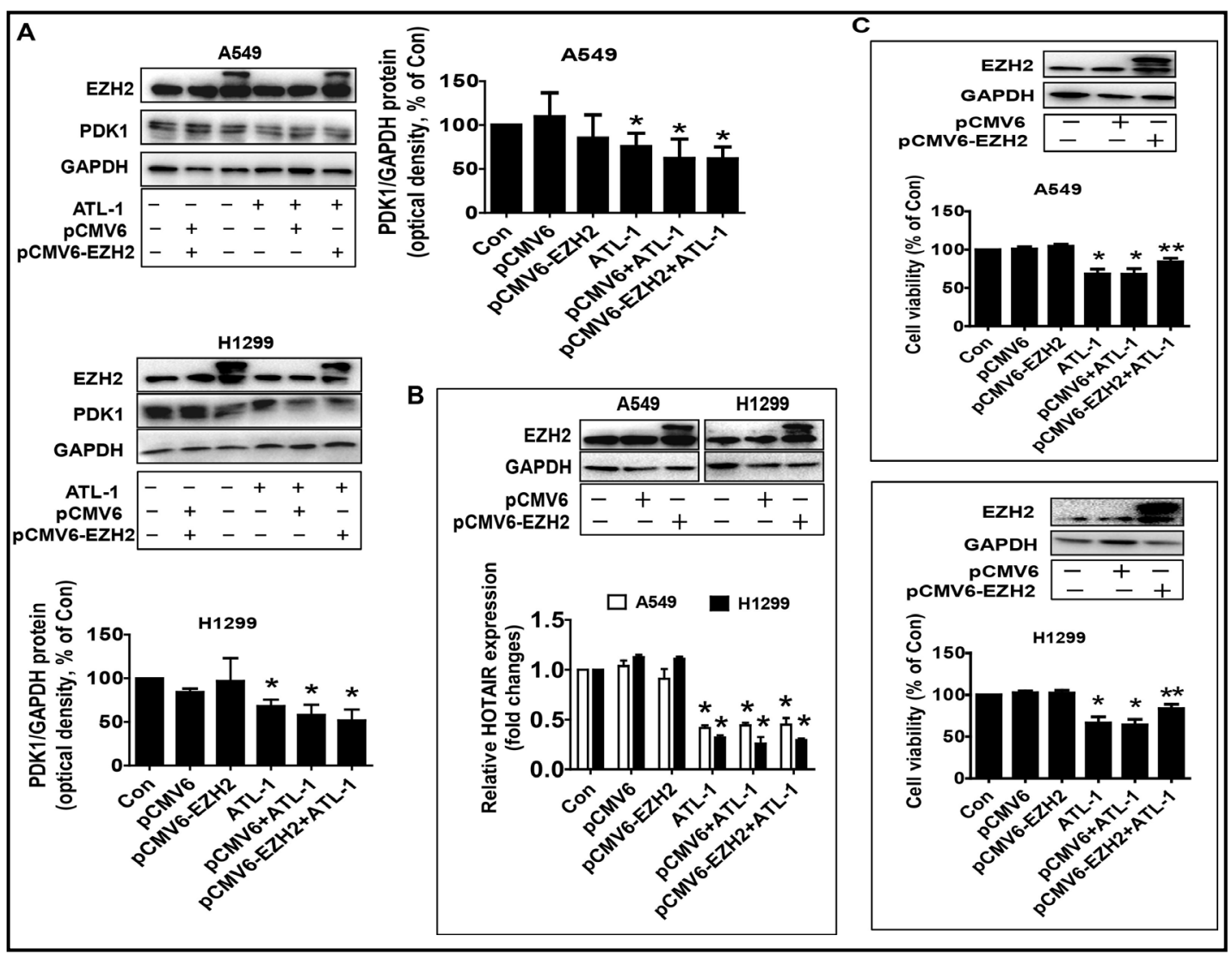

Fig. 6. Overexpressed EZH2 had no effects on PDK1 and HOTAIR. A-B, A549 and H1299 cells were transfected with the control and the EZH2 overexpression vector for $24 \mathrm{~h}$ before exposing the cells to ATL- 1 for an additional $24 \mathrm{~h}$. Afterwards, the protein expression of PDK1 and mRNA levels of HOTAIR were measured by Western blot and qRT-PCR, respectively. Insert on the upper panel in B represented the protein levels of EZH2 as determined by Western blot. GAPDH was used as internal control. C, A549 and H1299 cells were transfected with the control and the EZH2 overexpression vector for $24 \mathrm{~h}$ before exposing the cells to the ATL-1 for an additional $24 \mathrm{~h}$, followed by measuring the EZH2 protein and cell viability by Western blot and MTT assays as described in the Materials and Methods sections, respectively. Insert represented the EZH2 protein expression. The figures are the representative cropped gels/blots that have been run under the same experimental conditions. Values in bar graphs were given as the mean \pm SD from three independent experiments. *indicates significant difference as compared to the untreated control group $(\mathrm{P}<0.05)$. $* *$ indicates significant difference from the ATL-I alone $(\mathrm{P}<0.05)$.

with metastasis and poor prognosis. Moreover, HOTAIR promotes proliferation, survival, invasion, metastasis, and drug resistance in lung cancer cells $[13,44]$. However, so far, no connection between HOTAIR and PDK1 has been reported, and the function role of HOTAIR in mediating the anti-tumor effects of ATL-1 and EGFR-TKI remains unknown as well. For the first time, we observed the role of HOTAIR in mediating the effect of ATL-1 or EGFR-TKI in the inhibition of human lung cancer cells. Our results suggest that the repression and interaction of PDK1 and HOTAIR expression were involved in the anti-lung cancer effects of these agents. Regardless, whether epigenetically regulation of PDK1 gene promoter is activated by HOTAIR or vice versa, requires to be determined using Chip-qRT-PCR or RNA-pull-down assays. The expression pattern and potential function of IncRNAs in EGFR-TKI resistant NSCLC cells have also been reported. Disregulation of IncRNAs other than HOTAIR plays critical roles in EGFR-TKIs resistant NSCLC cells. The IncRNA-mediated EGFR-TKIs resistance might help us to improve clinical response rates and could be used as novel potential targets to reverse the EGFR-TKI resistance for NSCLC patients $[45,46]$. Our findings implied that targeting 
Xiao et al.: Repression of EZH2 Gene Expression by the Combination of Atractylenolide 1 and Erlotinib

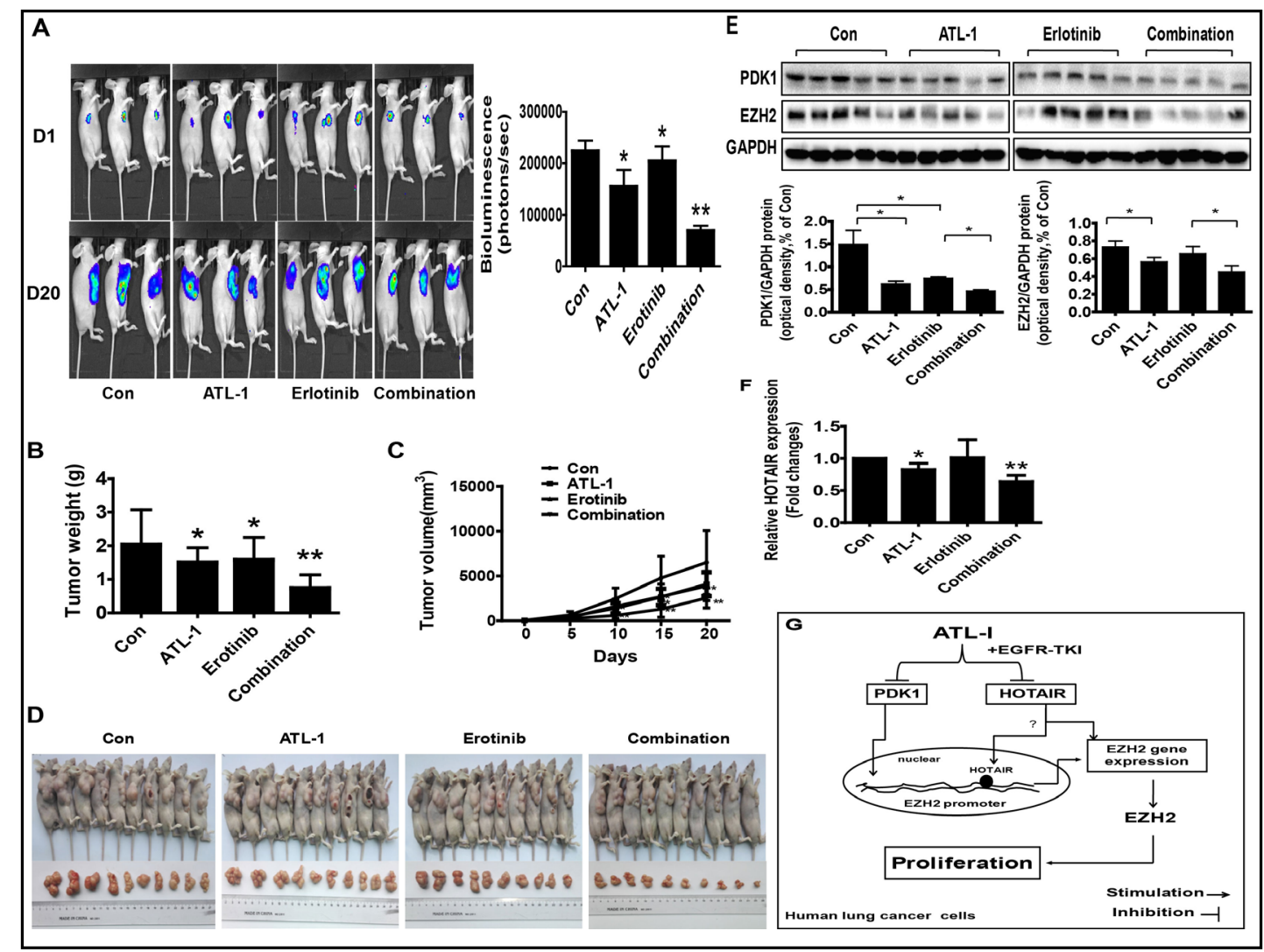

Fig. 7. ATL-1 inhibited tumor growth, levels of HOTAIR, and protein expressions of EZH2 and PDK1 in vivo. A, The tumor growth was monitored by injecting luciferin followed by measuring bioluminescence signals. Representative images are shown. B-C The xenografts were harvested on day 20, and the volume and weight of tumors were measured. D, The photographs of ATL-I $75 \mathrm{mg} / \mathrm{kg} /$ day alone or in the presence or absence of and erlotinib (50 mg/kg), and vehicle-treated xenografts derived from nude mice are shown. E-F, At the end of the experiments, xenograft tumors were isolated and processed for detecting PDK1 and EZH2 proteins, and HOTAIR mRNA levels by Western blot and qRT-PCR, respectively. Values in bar graphs were given as the mean \pm SD from three independent experiments. *indicates significant difference as compared to the untreated control group $(\mathrm{P}<0.05)$. ${ }^{* *}$ indicates significant difference from the ATL- 1 alone $(\mathrm{P}<0.05)$. G, The diagram shows that ATL-1 inhibits lung cancer cell growth through inhibition not only of PDK1 but also of IncRNA HOTAIR, which results in reduction of the EZH2 expression. The repression of PDK1 and HOTAIR, and interplay between HOTAIR and EZH2 coordinate to the overall effects of ATL-1. Importantly, the combination of ATL-1 and EGFR-TKI erlotinib exhibits synergy.

the critical oncogenes PDK1 and HOTAIR might be involved in the additive effects or even potential synergy of the combination of ATL- 1 and erlotinib in the inhibition of lung cancer cell growth.

In addition, we demonstrated an important role of EZH2 in this process. Our findings indicated that the reduction of EZH2 gene expression by ATL-1 and erlotinib was involved in the enhanced inhibition of lung cancer cell growth. This strengthens the notion that EZH2 is an important target in developing novel anti-cancer strategies [22, 23]. Consistent with our results, several natural products have been reported to have potential for the prevention and treatment of several cancer types via regulation of EZH2 through multiple mechanisms [47]. In addition, the genetic, transcriptional, and posttranscriptional dysregulation of EZH2 is frequently found in several cancer types. EZH2 promoted tumorigenesis by altering the expression of numerous tumor suppressor genes. Thus, the inhibition of EZH2 expression has been shown to be involved in the control of growth and progression of several cancer types [18-20,48], suggesting a critical role of this molecule. Previous studies indicated that 


\section{Cellular Physiology Cell Physiol Biochem 2018;49:1615-1632

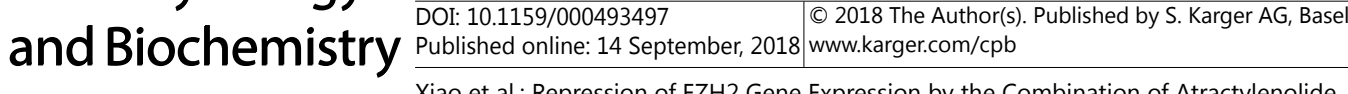 \\ 1 and Erlotinib}

lncRNA was capable of regulating target gene expression through interactions with RNA binding proteins. More importantly, lncRNA HOTAIR is physically associated with EZH2, leading to the regulation of EZH2 and other target gene expressions in various cancer cells $[32,41,42,49]$. Consistent with this, we observed reduced physical association between HOTAIR and EZH2 proteins treated with ATL-1, which influenced the repression of EZH2 and perhaps other genes; subsequently, this might also be involved in the effect of ATL-1 on lung cancer cell growth inhibition. Regardless, we suggest that more experiments (using methods, such as qRT-PCR-chromatin immunoprecipitation, among others) are still required to elucidate the detailed mechanism underlying the physical interaction of HOTAIR and EZH2. Expressions of EZH2 or other target genes may be involved in the ATL-1-inhibited human lung cancer growth. EZH2 is involved in multiple pathological processes related to carcinogenesis, proliferation, apoptosis, and metastasis [50,51]. We therefore reasoned that the expression or/and activities of HOTAIR affected by ATL-1 in lung cancer cells might depend on the interaction of HOTAIR and EZH2. Links of HOTAIR and EZH2 have been reported in several other studies. HOTAIR has been shown to interact with and recruit polycomb repressive complex 2 (PRC2) to regulate the chromosome occupancy through EZH2, which then leads to histone $\mathrm{H} 3$ lysine 27 trimethylation (H3K27me3) of certain genes [40]. HOTAIR could also bind to EZH2; resulting in the stimulation of growth, progression, and metastasis in several cancer types [30-32, 49, 52]. Thus, blocking the ability of HOTAIR to interact with EZH2 and subsequently inhibit the HOTAIR-EZH2 pathway might unveil a novel cancer therapeutic approach [53]. We showed the regulation of EZH2 by PDK1; still, more studies are required to determine if there are true PDK1 binding sites in the EZH2 promoter or/and whether a physical association exists between the PDK1 and EZH2 proteins affected by ATL-1 in the presence or absence of erlotinib. Overall, these observations demonstrated the links and interactions among PDK1, HOTAIR, and EZH2 in the regulation of the biological functions and lung cancer cell growth treated with the ATL-1 and erlotinib, suggesting that repressions of PDK1 and HOTAIR, at both translational and transcriptional levels, have been involved in mediating the ATL-reduced EZH2 expression. This further illustrates the associated mechanism in the inhibition of PDK1 and lncRNA HOTAIR, and subsequently reduces the expression of EZH2. In addition, our results also highlight EZH2 as a rational target for therapeutic intervention in NSCLC.

Our in vivo results fit the observation in vitro, further confirming the inhibitory effect of ATL-1 and erlotinib on lung tumor growth, and regulation of PDK1, HOTAIR, and EZH2 expressions. The doses of ATL-1 used were based on another study, which showed significant inhibitory effects on tumor growth without noticeable toxicity [38]. In addition, the combination of erlotinib with other agents, showing even greater effects in inhibition of human cancer cells through multiple molecular mechanisms, have also been reported in other studies [54-56]. Our findings suggest that ATL-1 might sensitize or enhance the effect of erlotinib in the controlling human lung cancer cell growth or vice versa via targeting the tumor suppressor target genes PDK1 and EZH2 [57], and HOTAIR signaling axis. This implies a potential additive synergy of these agents in EGFR-TKI resistance setting. This also highlighted a critical step forward towards treating EGFR-TKI resistant human lung cancer, thus implying a potential therapeutic strategy for clinical patients. We suggest that more studies are needed to further determine the important role of EZH2 in this process, such as using cells that are stably transfected with overexpression of EZH2 gene in animal models.

\section{Conclusion}

In conclusion, our results show that ATL-1 inhibits lung cancer cell growth via inhibition not only of PDK1 but also of IncRNA HOTAIR, which results in the reduction of one downstream effectors EZH2 expression. The interplay between HOTAIR and EZH2, and the repression of PDK1 and HOTAIR coordinate the overall effects of ATL-1. Importantly, the combination of ATL-1 and EGFR-TKI erlotinib exhibits synergy (Fig. 7F). Thus, targeting the 


\section{Cellular Physiology Cell Physiol Biochem 2018;49:1615-1632

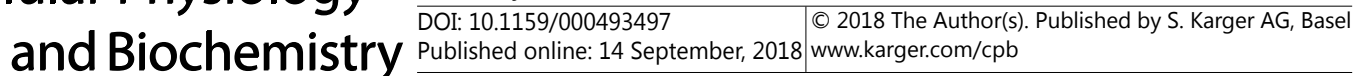 \\ Xiao et al.: Repression of EZH2 Gene Expression by the Combination of Atractylenolide 1 and Erlotinib}

PDK1- and HOTAIR-mediated the downstream molecule EZH2 by a combination of ATL-1 and erlotinib potentially facilitate the development of an additional novel strategy to combat lung cancer.

\section{Acknowledgements}

This work was partially supported by grants from the National Nature Scientific Foundation of China (Nos. 81272614, 81403216, 81673845, and 81703551), the Science and Technology Program of Guangzhou (No. 201607010385), the Discipline of Integrated Chinese and Western Medicine in Guangzhou University of Chinese Medicine (No. A1-AfD018161Z1513), the Special Science and Technology Join fund from Guangdong Provincial Department of Science and Technology-Guangdong Academy of Traditional Chinese Medicine (Nos. 2012A032500011 and 2014A020221024), Science and Technology Planning Project of Guangdong Province (No. 2017A050506042), and the Specific Research Fund for TCM Science and Technology of Guangdong Provincial Hospital of Chinese Medicine (Nos. YK2013B2N13 and YN2015MS19).

\section{Disclosure Statement}

The authors declare that they have no competing interests.

\section{References}

-1 Siegel RL, Miller KD, Jemal A: Cancer statistics, 2016. CA Cancer J Clin 2016;66:7-30.

-2 Hirsch FR, Scagliotti GV, Mulshine JL, Kwon R, Curran WJ, Jr., Wu YL, Paz-Ares L: Lung cancer: Current therapies and new targeted treatments. Lancet 2017;389:299-311.

-3 Burotto M, Manasanch EE, Wilkerson J, Fojo T: Gefitinib and erlotinib in metastatic non-small cell lung cancer: A meta-analysis of toxicity and efficacy of randomized clinical trials. Oncologist 2015;20:400-410.

4 Tan CS, Gilligan D, Pacey S: Treatment approaches for egfr-inhibitor-resistant patients with non-small-cell lung cancer. Lancet Oncol 2015;16:e447-459.

5 Pao W, Miller VA, Politi KA, Riely GJ, Somwar R, Zakowski MF, Kris MG, Varmus H: Acquired resistance of lung adenocarcinomas to gefitinib or erlotinib is associated with a second mutation in the egfr kinase domain. PLoS Med 2005;2:e73.

-6 Song HP, Hou XQ Li RY, Yu R, Li X, Zhou SN, Huang HY, Cai X, Zhou C: Atractylenolide i stimulates intestinal epithelial repair through polyamine-mediated ca2+ signaling pathway. Phytomedicine 2017;28:27-35.

7 Li W, Zhi W, Liu F, He Z, Wang X, Niu X: Atractylenolide i restores ho-1 expression and inhibits ox-ldlinduced vsmcs proliferation, migration and inflammatory responses in vitro. Exp Cell Res 2017;353:26-34.

-8 More SV, Choi DK: Atractylenolide-i protects human sh-sy5y cells from 1-methyl-4-phenylpyridiniuminduced apoptotic cell death. Int J Mol Sci 2017;18.

-9 Liu H, Zhang G, Huang J, Ma S, Mi K, Cheng J, Zhu Y, Zha X, Huang W: Atractylenolide i modulates ovarian cancer cell-mediated immunosuppression by blocking md-2/tlr4 complex-mediated myd88/nf-kappab signaling in vitro. J Transl Med 2016;14:104.

10 Huang JM, Zhang GN, Shi Y, Zha X, Zhu Y, Wang MM, Lin Q, Wang W, Lu HY, Ma SQ Cheng J, Deng BF: Atractylenolide-i sensitizes human ovarian cancer cells to paclitaxel by blocking activation of tlr4/myd88dependent pathway. Sci Rep 2014;4:3840.

11 Ma L, Mao R, Shen K, Zheng Y, Li Y, Liu J, Ni L: Atractylenolide i-mediated notch pathway inhibition attenuates gastric cancer stem cell traits. Biochem Biophys Res Commun 2014;450:353-359.

12 Xiao Q Zheng F, Wu J, Tang Q, Wang W, Hann SS: Activation of erk and mutual regulation of stat3 and sp1 contribute to inhibition of pdk1 expression by atractylenolide- 1 in human lung cancer cells. Cell Physiol Biochem 2017;43:2353-2366. 


\section{Cellular Physiology Cell Physiol Biochem 2018;49:1615-1632 \begin{tabular}{ll|l} 
DOI: 10.1159/000493497 & (c) 2018 The Author(s). Published by S. Karger AG, Basel \\
www.karger.com/cpb
\end{tabular}}

Xiao et al.: Repression of EZH2 Gene Expression by the Combination of Atractylenolide

1 and Erlotinib

13 Loewen G, Jayawickramarajah J, Zhuo Y, Shan B: Functions of IncRNA hotair in lung cancer. J Hematol Oncol 2014;7:90.

14 Malek E, Jagannathan S, Driscoll JJ: Correlation of long non-coding RNA expression with metastasis, drug resistance and clinical outcome in cancer. Oncotarget 2014;5:8027-8038.

15 Wu Y, Zhang L, Wang Y, Li H, Ren X, Wei F, Yu W, Wang X, Zhang L, Yu J, Hao X: Long noncoding RNA hotair involvement in cancer. Tumour Biol 2014;35:9531-9538.

-16 Tang L, Shen H, Li X, Li Z, Liu Z, Xu J, Ma S, Zhao X, Bai X, Li M, Wang Q Ji J: miR-125a-5p decreases after long non-coding RNA hotair knockdown to promote cancer cell apoptosis by releasing caspase 2. Cell Death Dis 2016;7:e2137.

17 Qiu JJ, Wang Y, Ding JX, Jin HY, Yang G, Hua KQ: The long non-coding RNA hotair promotes the proliferation of serous ovarian cancer cells through the regulation of cell cycle arrest and apoptosis. Exp Cell Res 2015;333:238-248.

18 Liu Y, Peng J, Sun T, Li N, Zhang L, Ren J, Yuan H, Kan S, Pan Q, Li X, Ding Y, Jiang M, Cong X, Tan M, Ma Y, Fu D, Cai S, Xiao Y, Wang X, Qin J: Epithelial EZH2 serves as an epigenetic determinant in experimental colitis by inhibiting tnfalpha-mediated inflammation and apoptosis. Proc Natl Acad Sci U S A 2017;114:E3796-E3805.

19 Liu X, Wu Q, Li L: Functional and therapeutic significance of EZH2 in urological cancers. Oncotarget 2017.

20 Liu D, Li Y, Luo G, Xiao X, Tao D, Wu X, Wang M, Huang C, Wang L, Zeng F, Jiang G: LncRNA spry4-it1 sponges miR-101-3p to promote proliferation and metastasis of bladder cancer cells through up-regulating EZH2. Cancer Lett 2017;388:281-291.

21 Liu Y, Yu K, Li M, Zeng K, Wei J, Li X, Liu Y, Zhao D, Fan L, Yu Z, Wang Y, Li Z, Zhang W, Bai Q, Yan Q, Guo Y, Wang Z, Guo S: EZH2 overexpression in primary gastrointestinal diffuse large b cell lymphoma and its association with the clinicopathological features. Hum Pathol 2017.

-22 Mohammad F, Weissmann S, Leblanc B, Pandey DP, Hojfeldt JW, Comet I, Zheng C, Johansen JV, Rapin N, Porse BT, Tvardovskiy A, Jensen ON, Olaciregui NG, Lavarino C, Sunol M, de Torres C, Mora J, Carcaboso $\mathrm{AM}$, Helin K: EZH2 is a potential therapeutic target for $\mathrm{h} 3 \mathrm{k} 27 \mathrm{~m}$-mutant pediatric gliomas. Nat Med 2017;23:483-492.

23 Ihira K, Dong P, Xiong Y, Watari H, Konno Y, Hanley SJ, Noguchi M, Hirata N, Suizu F, Yamada T, Kudo M, Sakuragi N: EZH2 inhibition suppresses endometrial cancer progression via miR-361/twist axis. Oncotarget 2017;8:13509-13520.

24 Wang X, Cao W, Zhang J, Yan M, Xu Q, Wu X, Wan L, Zhang Z, Zhang C, Qin X, Xiao M, Ye D, Liu Y, Han Z, Wang S, Mao L, Wei W, Chen W: A covalently bound inhibitor triggers EZH2 degradation through chip-mediated ubiquitination. EMBO J 2017;36:1243-1260.

25 Yamamoto I, Nosho K, Kanno S, Igarashi H, Kurihara H, Ishigami K, Ishiguro K, Mitsuhashi K, Maruyama R, Koide H, Okuda H, Hasegawa T, Sukawa Y, Okita K, Takemasa I, Yamamoto H, Shinomura Y, Nakase H: EZH2 expression is a prognostic biomarker in patients with colorectal cancer treated with anti-egfr therapeutics. Oncotarget 2017;8:17810-17818.

26 Yang ZY, Yang F, Zhang YL, Liu B, Wang M, Hong X, Yu Y, Zhou YH, Zeng H: LncRNA-ancr down-regulation suppresses invasion and migration of colorectal cancer cells by regulating EZH2 expression. Cancer Biomark 2017;18:95-104.

-27 Shahabipour F, Caraglia M, Majeed M, Derosa G, Maffioli P, Sahebkar A: Naturally occurring anti-cancer agents targeting EZH2. Cancer Lett 2017.

28 Li L, Wu J, Zheng F, Tang Q, Wu W, Hann SS: Inhibition of EZH2 via activation of sapk/jnk and reduction of p65 and dnmt1 as a novel mechanism in inhibition of human lung cancer cells by polyphyllin i. J Exp Clin Cancer Res 2016;35:112.

29 Wu J, Tang Q, Yang L, Chen Y, Zheng F, Hann SS: Interplay of DNA methyltransferase 1 and EZH2 through inactivation of stat 3 contributes to beta-elemene-inhibited growth of nasopharyngeal carcinoma cells. Sci Rep 2017;7:509.

30 Wu Y, Zhang L, Zhang L, Wang Y, Li H, Ren X, Wei F, Yu W, Liu T, Wang X, Zhou X, Yu J, Hao X: Long noncoding RNA hotair promotes tumor cell invasion and metastasis by recruiting EZH2 and repressing e-cadherin in oral squamous cell carcinoma. Int J Oncol 2015;46:2586-2594.

31 Zhang K, Sun X, Zhou X, Han L, Chen L, Shi Z, Zhang A, Ye M, Wang Q, Liu C, Wei J, Ren Y, Yang J, Zhang J, $\mathrm{Pu}$ P, Li M, Kang C: Long non-coding RNA hotair promotes glioblastoma cell cycle progression in an EZH2 dependent manner. Oncotarget 2015;6:537-546. 


\section{Cellular Physiology Cell Physiol Biochem 2018;49:1615-1632 \begin{tabular}{l|l|l} 
DOI: $10.1159 / 000493497$ & (c) 2018 The Author(s). Published by S. Karger AG, Basel
\end{tabular} and Biochemistry

Xiao et al.: Repression of EZH2 Gene Expression by the Combination of Atractylenolide

1 and Erlotinib

32 Li CH, Xiao Z, Tong JH, To KF, Fang X, Cheng AS, Chen Y: EZH2 coupled with hotair to silence microRNA-34a by the induction of heterochromatin formation in human pancreatic ductal adenocarcinoma. Int J Cancer 2017;140:120-129.

33 Zheng F, Tang Q Wu J, Zhao S, Liang Z, Li L, Wu W, Hann S: P38alpha mapk-mediated induction and interaction of foxo3a and p53 contribute to the inhibited-growth and induced-apoptosis of human lung adenocarcinoma cells by berberine. J Exp Clin Cancer Res 2014;33:36.

34 Chou TC: Drug combination studies and their synergy quantification using the chou-talalay method. Cancer Res 2010;70:440-446.

-35 Hann SS, Chen J, Wang Z, Wu J, Zheng F, Zhao S: Targeting ep4 by curcumin through cross talks of ampdependent kinase alpha and p38 mitogen-activated protein kinase signaling: The role of pgc-1alpha and sp1. Cell Signal 2013;25:2566-2574.

-36 Hong Z, Cao X, Li N, Zhang Y, Lan L, Zhou Y, Pan X, Shen L, Yin Z, Luo L: Luteolin is effective in the non-small cell lung cancer model with $1858 \mathrm{r} / \mathrm{t} 790 \mathrm{~m}$ egf receptor mutation and erlotinib resistance. Br J Pharmacol 2014;171:2842-2853.

-37 Li R, Hu Z, Sun SY, Chen ZG, Owonikoko TK, Sica GL, Ramalingam SS, Curran WJ, Khuri FR, Deng X: Niclosamide overcomes acquired resistance to erlotinib through suppression of stat 3 in non-small cell lung cancer. Mol Cancer Ther 2013;12:2200-2212.

38 Yu R, Yu BX, Chen JF, Lv XY, Yan ZJ, Cheng Y, Ma Q: Anti-tumor effects of atractylenolide i on bladder cancer cells. J Exp Clin Cancer Res 2016;35:40.

-39 Mo Y, Lu Y, Wang P, Huang S, He L, Li D, Li F, Huang J, Lin X, Li X, Che S, Chen Q: Long non-coding RNA xist promotes cell growth by regulating miR-139-5p/pdk1/akt axis in hepatocellular carcinoma. Tumour Biol 2017;39:1010428317690999.

40 Zhang J, Zhang P, Wang L, Piao HL, Ma L: Long non-coding RNA hotair in carcinogenesis and metastasis. Acta Biochim Biophys Sin (Shanghai) 2014;46:1-5.

-41 Bao X, Ren T, Huang Y, Sun K, Wang S, Liu K, Zheng B, Guo W: Knockdown of long non-coding RNA hotair increases miR-454-3p by targeting stat 3 and atg 12 to inhibit chondrosarcoma growth. Cell Death Dis 2017;8:e2605.

42 Ning X, Shi Z, Liu X, Zhang A, Han L, Jiang K, Kang C, Zhang Q: Dnmt1 and EZH2 mediated methylation silences the microRNA-200b/a/429 gene and promotes tumor progression. Cancer Lett 2015;359:198205.

-43 Wu YL, Zhou C, Liam CK, Wu G, Liu X, Zhong Z, Lu S, Cheng Y, Han B, Chen L, Huang C, Qin S, Zhu Y, Pan H, Liang H, Li E, Jiang G, How SH, FeRNAndo MC, Zhang Y et al.: First-line erlotinib versus gemcitabine/ cisplatin in patients with advanced egfr mutation-positive non-small-cell lung cancer: Analyses from the phase iii, randomized, open-label, ensure study. Ann Oncol 2015;26:1883-1889.

-44 Xia M, Yao L, Zhang Q Wang F, Mei H, Guo X, Huang W: Long noncoding RNA hotair promotes metastasis of renal cell carcinoma by up-regulating histone h3k27 demethylase jmjd3. Oncotarget 2017;8:19795-19802.

-45 Ma P, Zhang M, Nie F, Huang Z, He J, Li W, Han L: Transcriptome analysis of egfr tyrosine kinase inhibitors resistance associated long noncoding RNA in non-small cell lung cancer. Biomed Pharmacother 2017;87:20-26.

-46 Dong S, Qu X, Li W, Zhong X, Li P, Yang S, Chen X, Shao M, Zhang L: The long non-coding RNA, gas5, enhances gefitinib-induced cell death in innate egfr tyrosine kinase inhibitor-resistant lung adenocarcinoma cells with wide-type egfr via downregulation of the igf-1r expression. J Hematol Oncol 2015;8:43.

-47 Shahabipour F, Caraglia M, Majeed M, Derosa G, Maffioli P, Sahebkar A: Naturally occurring anti-cancer agents targeting EZH2. Cancer Lett 2017;400:325-335.

48 Yamagishi M, Uchimaru K: Targeting EZH2 in cancer therapy. Curr Opin Oncol 2017;29:375-381.

49 Chen WM, Chen WD, Jiang XM, Jia XF, Wang HM, Zhang QJ, Shu YQ, Zhao HB: Hox transcript antisense intergenic RNA represses e-cadherin expression by binding to EZH2 in gastric cancer. World J Gastroenterol 2017;23:6100-6110.

50 Zhang DM, Lin ZY, Yang ZH, Wang YY, Wan D, Zhong JL, Zhuang PL, Huang ZQ, Zhou B, Chen WL: IncRNA h19 promotes tongue squamous cell carcinoma progression through beta-catenin/gsk3beta/emt signaling via association with EZH2. Am J Transl Res 2017;9:3474-3486.

-51 Chen QN, Chen X, Chen ZY, Nie FQ Wei CC, Ma HW, Wan L, Yan S, Ren SN, Wang ZX: Long intergenic noncoding RNA 00152 promotes lung adenocarcinoma proliferation via interacting with EZH2 and repressing il24 expression. Mol Cancer 2017;16:17. 


\section{Cellular Physiology Cell Physiol Biochem 2018;49:1615-1632}

\begin{tabular}{ll|l|l|l|l|l|l} 
O 2018 The Author(s). Published by S. Karger AG, Basel \\
and Biochemistry
\end{tabular}

Xiao et al.: Repression of EZH2 Gene Expression by the Combination of Atractylenolide

1 and Erlotinib

-52 Ma Z, Huang H, Wang J, Zhou Y, Pu F, Zhao Q, Peng P, Hui B, Ji H, Wang K: Long non-coding RNA snhg15 inhibits p15 and klf2 expression to promote pancreatic cancer proliferation through EZH2-mediated h3k27me3. Oncotarget 2017;8:84153-84167.

53 Ozes AR, Wang Y, Zong X, Fang F, Pilrose J, Nephew KP: Therapeutic targeting using tumor specific peptides inhibits long non-coding RNA hotair activity in ovarian and breast cancer. Sci Rep 2017;7:894.

54 Sano Y, Hashimoto E, Nakatani N, Abe M, Satoh Y, Sakata K, Fujii T, Fujimoto-Ouchi K, Sugimoto M, Nagahashi S, Aoki M, Motegi H, Sasaki E, Yatabe Y: Combining onartuzumab with erlotinib inhibits growth of non-small cell lung cancer with activating egfr mutations and hgf overexpression. Mol Cancer Ther 2015;14:533-541.

55 Stahlhut C, Slack FJ: Combinatorial action of microRNAs let-7 and miR-34 effectively synergizes with erlotinib to suppress non-small cell lung cancer cell proliferation. Cell Cycle 2015;14:2171-2180.

56 Rosell R, Dafni U, Felip E, Curioni-Fontecedro A, Gautschi O, Peters S, Massuti B, Palmero R, Aix SP, Carcereny E, Fruh M, Pless M, Popat S, Kotsakis A, Cuffe S, Bidoli P, Favaretto A, Froesch P, Reguart N et al.: Erlotinib and bevacizumab in patients with advanced non-small-cell lung cancer and activating egfr mutations (belief): An inteRNAtional, multicentre, single-arm, phase 2 trial. Lancet Respir Med 2017;5:435-444.

57 Mei LL, Qiu YT, Zhang B, Shi ZZ: MicroRNAs in esophageal squamous cell carcinoma: Potential biomarkers and therapeutic targets. Cancer Biomark 2017;19:1-9. 